\title{
HIGH STABILITY AND LOW EMISSIONS BURNERS USING KARLOWITZ EFFECT IN CONICAL BURNERS
}

NICOLAE ANTONESCU - Assistant professor, PhD, Technical University of Civil Engineering, Faculty for Building Services Engineering, e-mail: nicuant@yahoo.com

PAUL-DAN STANESCU - Professor, PhD, Technical University of Civil Engineering, Faculty for Building Services Engineering, e-mail: pauldan.stanescu@yahoo.com

\begin{abstract}
The conical tunnel burner is an improvement of the cylindrical tunnel burner because, by maintaining all its advantages by means of burning intensification, it may also insure the flame stabilization in a wide range of regulation with considerable diminished pressure losses. Technical applications for the conical furnace burner can vary due to the limited dimensions required by the system, as well as the important thermal loads, and also because of the burning stability characteristic that spreads over an important range of regulation. The low costs required by the burner, generated mainly by its simple construction, also raise the interest for this technical solution. A physical model is proposed for the ignition and flame front stabilization. The flame front stabilization contains different steps from the ignition moment to final flame front stabilization, with specific flame front geometries and specific locations along the burner axis. The installation realised by the authors allowed the experimental study of the burning process in conical furnaces, in order to determine the temperature fields and the flame profiles. The physical model developed for this new type of application and the experimental data sets obtained (along with their interpretation) make the subject of this paper.
\end{abstract}

Keywords: intensified burning process, stabilization, Karlowitz effect, conical burner

\section{Introduction}

The cylindrical tunnel burner was the first accomplishment of intensified burning processes and we can mention as that the first historical application of the cylindrical tunnel burner was patented in France in 1907. The patent has been obtained by Traian Vuia, one of the great Romanian scientists, and referred to airplane applications, because of its burning thermal loads up to 1000 times higher than for normal atmospheric burners characterized by laminar planar flame speed.

In our researches we applied the tunnel burner burning process intensification technique to our specific burner geometry. The conical geometry that we chose has revealed important functional and technical advantages, also maintaining the characteristic advantages for the cylindrical tunnel burner intensified burning process.

For the burning processes with lateral confinement it was observed that measured turbulence after the burning process was greater than the determined one from the calculus of flow speeds, even when the molecular and thermal expansion was taken into account. The intensification of the burning process due to the additional turbulization, also called "self-turbulization" induced by the flame front and known as "Karlowitz effect", was theoretically studied for the cylindrical tunnel burners [1]. The process is based on the phenomenon of conversion of flame front transversal speeds energies into turbulent energies (vortexes) because of the flow limitation imposed by the burner walls that doesn't allow lateral expansion. This kind of process is generally called "with non-slip boundary conditions at the wall" and from different researches [2] - [5] , it resulted that the burning process speed rises up to 10 times due to self turbulisation in cylindrical tunnel burners by respect to laminar planar flame speed. In the study "Turbulent burning, flame 
acceleration, explosion triggering" [6] the author indicates that only by taking into account the effect of non-slip boundary conditions in addition to general flow turbulence, the model for the burning process (applied to cylindrical burners) can match the experimental results.

\section{Construction and functioning principle}

The conical tunnel burner is fed with air-combustible mixture in the kinetic dosage domain through a tube with interior diameter smaller than the minimal ignition diameter, in order to avoid the flame return phenomenon. In the case of high speed flows of combustible mixtures the minimal ignition diameter is considerably larger then for the case of stationary ignition, fact resulting from the ignition equations analyze. The construction and functioning principle of the conical burner is described in Figure1.

The gaseous fuel and the necessary air for the burning process are fed in the upstream end of a homogenization element realized from a cylinder filled with non-aerodynamic geometry bodies randomly disposed. The mixture must be in the kinetic burning domain and well homogenized, in order to reduce flame stabilization variations.

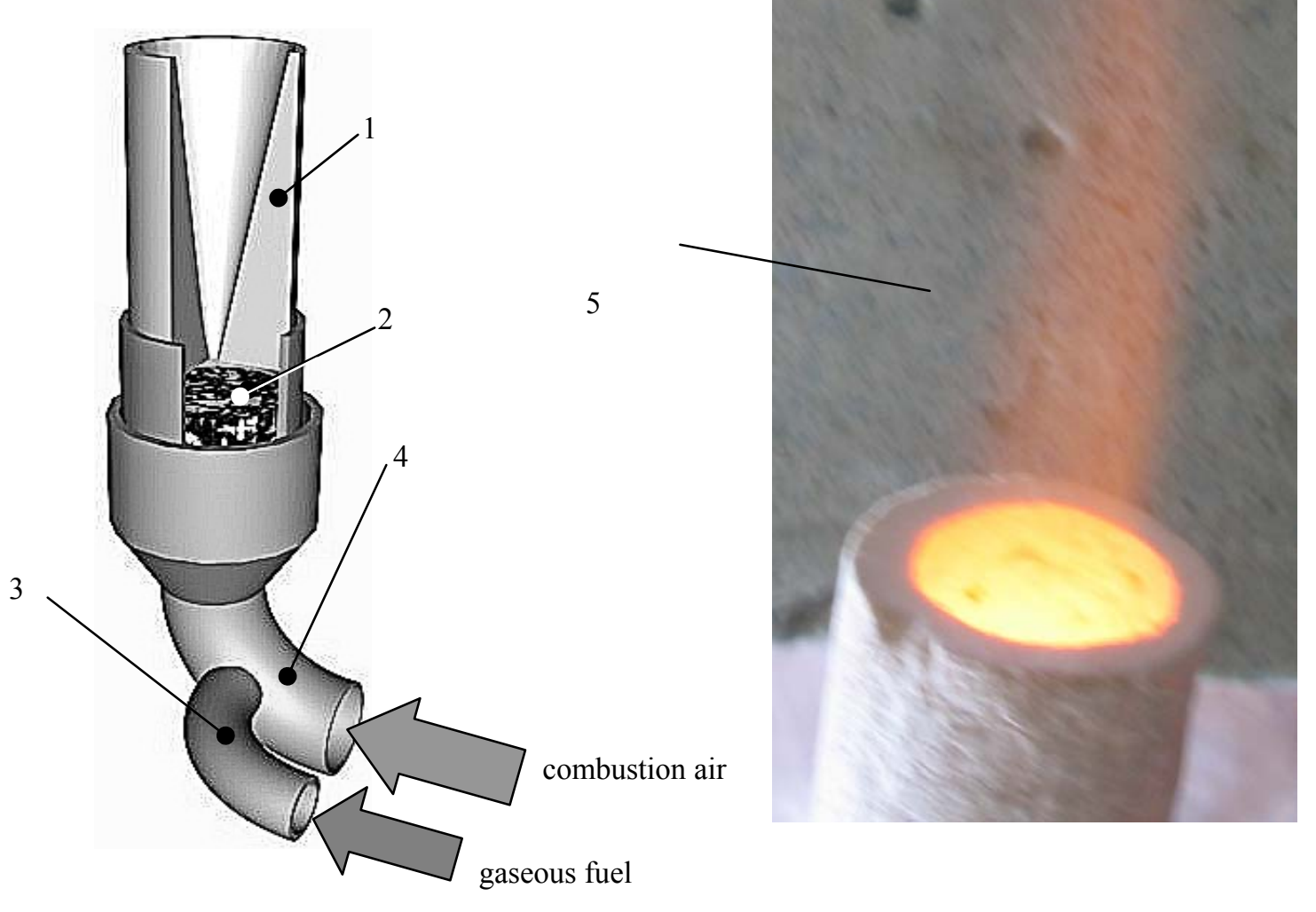

1. conical refractory body; 2. homogenization element; 3. gaseous fuel intake; 4. air intake; 5. photo of the working burner (opened end)

Fig 1 - Conical tunnel furnace

At the moment of superior ignition, at the opened end of the conical burner, the flame front will move upstream (towards the intake nozzle of the burner) in a stable position, characteristic for the cold walls ignition process. The stability condition is reached if the turbulent burning speed in the wall vicinity (considering the extinguishing effect generated by the cold surface) is equal to the flow speed in the hydraulic boundary layer (considering speed variation from zero to mean stream value).

In the very next moment the flame front additional turbulence appears due to non-slip boundary conditions at the wall imposed by the conical geometry of the burner. This increase of the burning speed generates a further upstream movement of the flame front in a new stable ignition position where, due to the conical form of the burner, the flame turbulization further grows, and 
so on, till the flow speed equalize the enhanced burning speed due to the Karlowitz effect. The equilibrium between the burning process intensification and marginal detachment of the flame due to upstream flow speed increase generated by the conical form of the burner is, generally speaking, a stable process, fact experimentally demonstrated by the real stabilization of the flame front at a certain axial distance from the intake nozzle of the conical burner.

As the wall temperature of the burner increases, due to heat transfer from the flue gases and the flame front, at a certain moment the combustible mixture ignition temperature will be reached and the flame front will adhere to the solid surface getting a new stable ignition position. The phenomenon between the primary ignition and final stabilization happens in a very short delay, by the order of seconds, due to high speeds and intense heat transfers involved. For the moment, in this experimental phase, those transient states will not be detailed. What was experimentally determined was that a few seconds after primary ignition the burning process is stable and fixed at a certain axial distance from the intake nozzle of the burner. The flame front stabilization is self regulated on different sections, closer to the intake nozzle, on smaller diameters of the cone, when debits diminish, and further from the nozzle when debits rise.

\section{Physical model}

A physical model can be deducted for describing the ignition and flame front stabilization. The flame front stabilization contains three different steps from the ignition moment to final flame front stabilization, with specific flame front geometries and specific locations along the burner axis. The evolution of the process is described in Figure 2.

In the first stage of the process (see Figure 2a), the burner is cold and the gaseous combustible mixture is ignited at the exhaust end of the burner by an external source (spark or hot gases). The flame front moves upstream towards the intake nozzle because flame return conditions are present, meaning that at least for one geometrical contour the speed of the turbulent burning process exceeds the speed of the flow (due to boundary layer speed distribution effect).

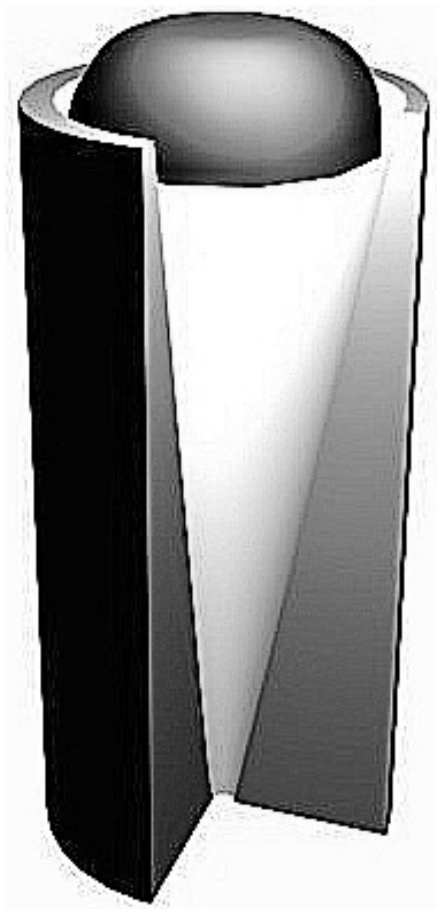

a. first stage of the process

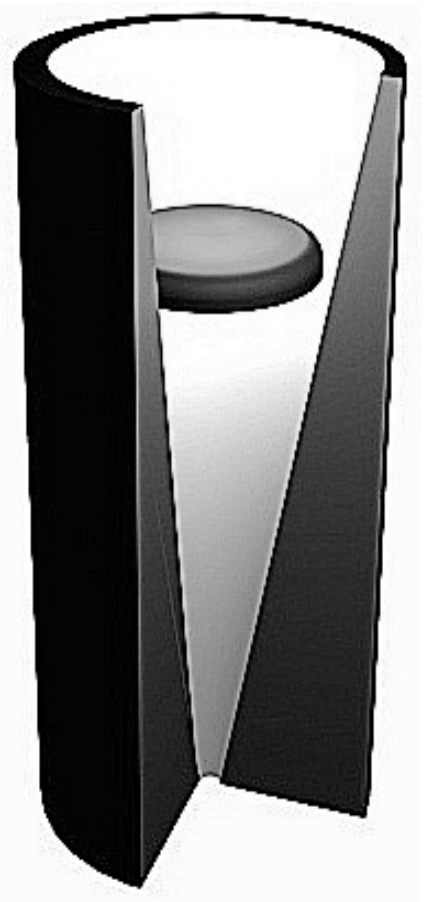

b. stabilization by the equality between flow speed in the boundary layer and the increased

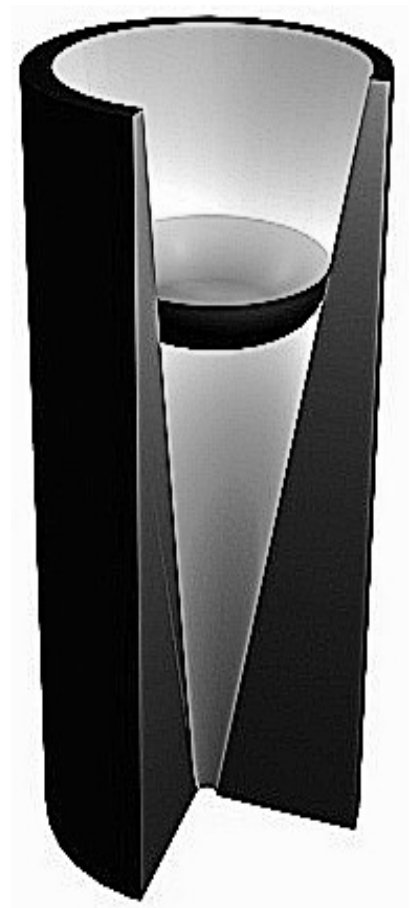

c. equal speed stabilization turbulent speed completed by hot surfaces ignition

Fig 2. - The three different types of flame front between ignition and final stabilization 
The gradient of the turbulent burning speed in the boundary layer zone has two different domains:

- near the wall, on a certain distance, the extinguishing effect of the cold wall is present and so the burning process is blocked because the flammable mixture temperature is reduced under the ignition point; for these zone the burning speed is null;

- beyond the cold wall extinguishing effect zone, the turbulent burning speed rapidly varies from zero to nominal values, due to the exponential dependence of the burning speed with the combustible mixture temperature;

The first stabilization contour may be point out for the equality of turbulent burning speed with the flow speed in the boundary layer.

In the second stage (see Figure $2 b$ ) the walls of the burner are still cold and the flame front stabilization corresponds to the first step model. Because of the lateral flow limitation, the Karlowitz effect appears, generating the self-turbulization of the flame front. The result is an increase of the turbulent burning speed due to the additional turbulence and so the flame front further migrates towards the intake nozzle, on a smaller section zone of the conical burner. The flame front is stable and the stabilization contour conditions are now generated by the equality between flow speed in the boundary layer and the increased turbulent speed, characteristic for the burning process after getting the additional Karlowitz effect turbulence.

In the third stage of the flame front stabilization, the burner wall reaches the ignition temperature for the gaseous combustible mixture, more precisely for the studied case the $780{ }^{\circ} \mathrm{C}$ value, and the flame front gets stabilization conditions directly on the burner wall. In this case, the equal speed stabilization conditions are completed by the hot surfaces ignition conditions. In the picture representing the third stage of flame front stabilization (see Figure 2c) it may be easily observed the plane form of the flame front that respects the speed distribution of the flow in the section and the upwards oriented stabilization contour due to direct ignition from the wall. The hot wall surface ignition comes in addition to turbulent stabilisation. The additional turbulization due to Karlowitz effect is well present in a conical geometry burner, although a certain lateral expansion is permitted to the flue gases in the flame front (the non-slip boundary condition is not total, as in the case of cylindrical burners). This is happening because this lateral expansion allowed by the burner's conical geometry is significantly less important than the expansion tendency generated by the dilatation of the air-combustible mixture in the burning process.

So, for the conical burner solution, the lateral constriction of the flow is present as in the case of the cylindrical tube burner, maintaining the intensified character of the burning process, but also bringing some important specific advantages:

- due to the conical geometry of the burner that generates a continuously wider flow section, a self stabilization of the flame front in a certain section along the flow is possible, unlike the case of the cylindrical burner where special stabilization systems must be used, otherwise the flame front will reach the combustible mixture intake nozzle;

- the self-stabilization process is valid in a wide regulation domain for the combustible mixture flow;

- the continuously wider flow section of the burning chamber leads to flow deceleration along the axis of the burner by comparison with the cylindrical burner and so the hydraulic pressure losses are significantly lower, with no significant implication for the stability process, because the self-turbulization is a local process and the widening of the flow section is negligible along the flame front depth;

- the flame front stabilization at the cylindrical burner may be realized only by the means of special geometry elements like peripheral recirculation chambers or diaphragms, unlike the conical burner that self-stabilizes the flame front, due to the variation of the 
flow section, at a certain distance from the intake nozzle, where the intensified turbulent burning speed of the mixture equals the mean speed of the flow;

- due to the fact that the combustible mixture enters through the entire section at the cylindrical burner, its stability limit is linked to the back-flame situation, unlike the case of the conical burner where the small intake section of the nozzle is characterized by flow speeds bigger than the turbulent burning speed even at low thermal charges.

As for the debit variation situation, due to the conical geometry of the burner, the flame front stabilization is self regulated on different conical tube diameters and so, if the combustible mixture debit decreases, its flow speed will also decrease and the stabilization diameter will also decrease, corresponding to a closer to the nozzle position than the previous one. Oppositely, if the debit rises, the stabilization process will move downstream along the burner axis.

The angle of the burner cone is limited to $12^{\circ}$, the detachment angle for free axial streams. If the angle surpasses this limit value, a Craya-Courtet boundary recirculation forms, generating a recirculation stabilization effect instead of a self-turbulization Karlowitz effect stabilization. Along with the increase of the cone angle the stabilization process will get closer to the case of wide furnaces burners' stabilization, with lower burning speeds and lower furnace thermal loads.

\section{Equational model}

At the ignition moment the flame front moves upstream in the conical tube due to back-flame conditions that appears because the free flame turbulent burning speed $u_{t}$ is greater than the flow speed $w$ anywhere in the exit section. The variation curves for the two speed values are represented in Figure 3.

The gradient of the flow speed in the boundary layer may be accepted as linear (Prandtl and Taylor), described by the equation [1]:

$$
g_{T}=0.023 \cdot \frac{w_{m}^{1.8} \cdot v^{0.8}}{D^{0.2}}
$$

where: $g_{T}$ is the speed gradient in the boundary layer, $w_{m}$ is the mean value of the flow speed, $v$ is the cinematic viscosity and $D$ is the tube diameter.

The gradient of the turbulent burning speed in the boundary layer zone has two different domains:

- near the wall the extinguishing effect is present and so $\mathrm{u}_{\mathrm{t}}=0$;

- beyond the cold wall extinguishing effect zone the turbulent burning speed rapidly varies from zero to nominal values, due to the exponential dependence of the burning speed by the combustible mixture temperature [7] (Bollinger):

$$
\frac{u_{T 1}}{u_{T 2}}=\left(\frac{T_{1}}{T_{2}}\right)^{1.4}
$$

Due to wall limited flame conditions the Karlowitz effect of burning speed raise takes place. Compared to the process in cylindrical geometry tunnel burners, the process in conical tunnel burners is affected by the flow section relaxation on radial direction, due to the specific geometry. The phenomenon for the conical geometry is illustrated in Figure 4. 

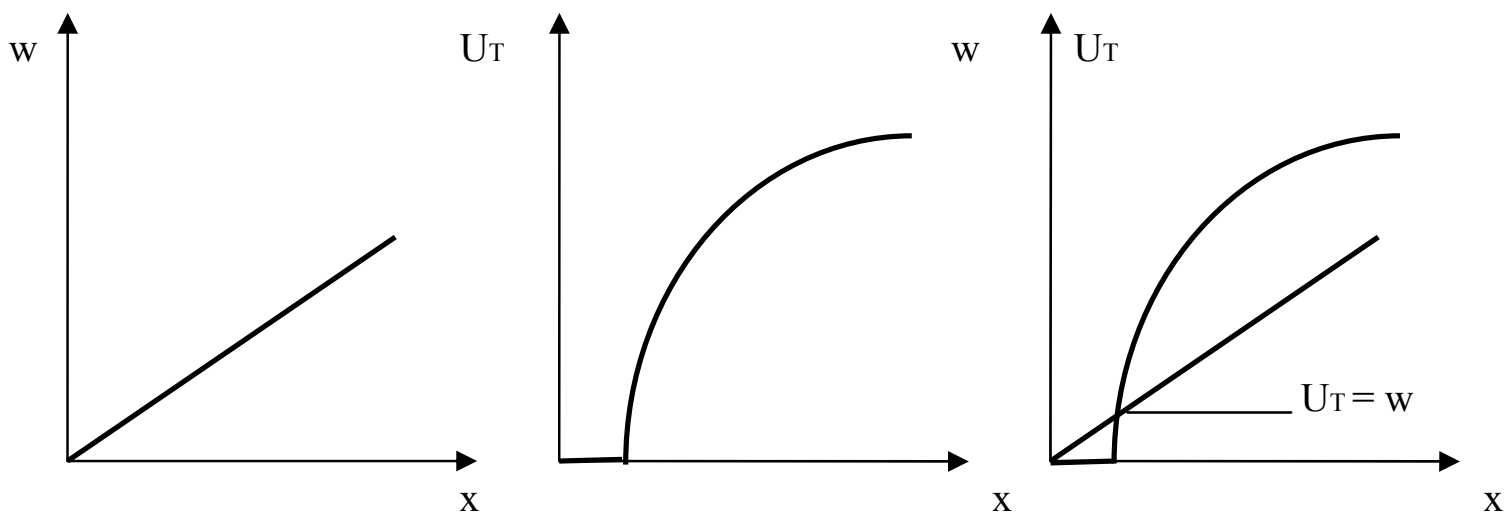

Fig 3. - The variation curves for the flow speed and for the burning speed

On a perpendicular direction on the momentary flame front, flow acceleration appears, due to burning process with flue gas formation and temperature raise from ignition temperature to theoretical burning temperature. In the hypothesis of a burning process with no chemical relaxation, the flame front acceleration from normal combustible mixture flow speed $u_{0}$ (and density $\rho_{0}$ ) to flame front flue gases flow speed $u_{T}$ (and density $\rho_{T}$ ), is given by the speed increase defined as:

$$
\Delta w_{f r}=u_{0} \cdot \frac{\rho_{0}-\rho_{T}}{\rho_{T}}
$$

This acceleration may effectively develop on axial direction (considering the general flow) but on radial direction it is confined by the solid walls of the burner and may not develop. If the walls are of cylindrical shape, the confinement is complete, but in the case of a conical geometry, a certain lateral expansion is permitted, in the limits of section increase due to $\beta / 2$ angle made by the wall with the main flow axis, as shown in Figure 4.

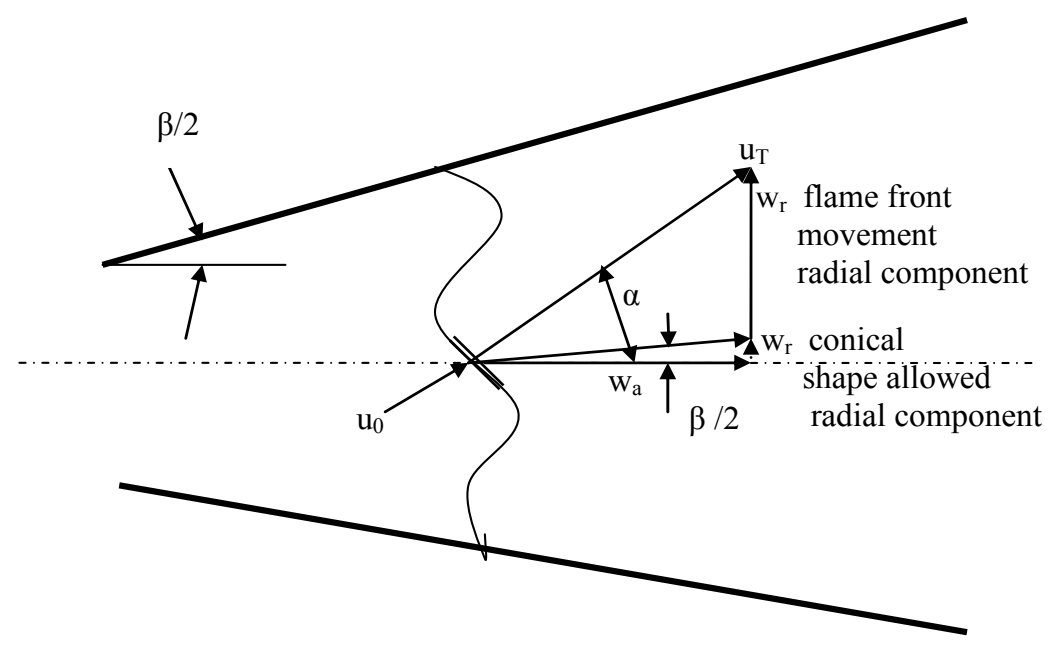

Fig 4. - Flame front in conical tube burner

The axial acceleration generated by the axial speed difference $\Delta w_{a x}$ has the expression:

$$
\Delta w_{a x}=u_{0} \cdot \frac{\rho_{0}-\rho_{T}}{\rho_{T}} \cdot \cos \alpha
$$

where $\alpha$ is the flame front mean angle, as defined in the Damköhler turbulent burning model [7].

Considering the lateral expansion allowed by the conical geometry, a radial acceleration can be considered as given by the speed difference on radial direction $\Delta w_{r}$ : 


$$
\Delta w_{r}=u_{0} \cdot \frac{\rho_{0}-\rho_{T}}{\rho_{T}} \cdot \cos \alpha \cdot \tan \left(\frac{\beta}{2}\right)
$$

Because in the Damköhler turbulent burning model the $\quad \alpha$ angle is defined by the relation $\cos \alpha=\mathrm{u}_{\mathrm{o}} / \mathrm{u}_{\mathrm{T}}$ the speed differences determining the axial and radial accelerations becomes:

$$
\Delta w_{a x}=u_{0} \cdot \frac{\rho_{0}-\rho_{T}}{\rho_{T}} \cdot \frac{u_{0}}{u_{T}}
$$

and

$$
\Delta w_{r}=u_{0} \cdot \frac{\rho_{0}-\rho_{T}}{\rho_{T}} \cdot \frac{u_{0}}{u_{T}} \cdot \tan \left(\frac{\beta}{2}\right)
$$

The total energy generated by the flame front acceleration is proportional with the square power of the speed difference:

$$
\Delta E_{f r} \approx\left(\Delta w_{f r}\right)^{2}=\left(u_{0} \cdot \frac{\rho_{0}-\rho_{T}}{\rho_{T}}\right)^{2}
$$

From the total acceleration energy generated by the flame front, only a part is consumed by the means of the axial component of the speed difference and by the means of the allowed (by the conical shape) radial speed difference energy and converted into effective gain of kinetic energy for the flow. The remaining energy, that transforms into additional turbulence (Karlowitz effect for conical geometries) will be the difference between total acceleration energy generated by the flame front and total kinetic energies gained by the flow both on axial and radial directions:

$$
\begin{aligned}
& \Delta E_{T} \approx\left(u_{0} \cdot \frac{\rho_{0}-\rho_{T}}{\rho_{T}}\right)^{2}-\left(u_{0} \cdot \frac{\rho_{0}-\rho_{T}}{\rho_{T}} \cdot \frac{u_{0}}{u_{T}}\right)^{2}-\left(u_{0} \cdot \frac{\rho_{0}-\rho_{T}}{\rho_{T}} \cdot \frac{u_{0}}{u_{T}} \cdot \tan \left(\frac{\beta}{2}\right)\right)^{2} \\
& \Delta E_{T} \approx\left(u_{0} \cdot \frac{\rho_{0}-\rho_{T}}{\rho_{T}}\right)^{2} \cdot\left[1-\left(\frac{u_{0}}{u_{T}}\right)^{2}-\left(\frac{u_{0}}{u_{T}}\right)^{2} \cdot \tan ^{2}\left(\frac{\beta}{2}\right)\right]
\end{aligned}
$$

and therefore:

$$
\frac{u_{T K}}{u_{T}}=\frac{\varepsilon+\frac{1}{\sqrt{3}} \cdot\left(u_{0} \cdot \frac{\rho_{0}-\rho_{T}}{\rho_{T}}\right) \cdot \sqrt{1-\left(\frac{u_{0}}{u_{T}}\right)^{2}-\left(\frac{u_{0}}{u_{T}}\right)^{2} \cdot \tan ^{2}\left(\frac{\beta}{2}\right)}}{\varepsilon}
$$

where: $u_{T K}$ is the intensified turbulent burning speed, $\mathrm{u}_{\mathrm{T}}$ is the free turbulent burning speed and $\varepsilon$ is the turbulence intensity of the room temperature combustible mixture flow.

\section{Experimental works}

The range of flows for witch the flame stability is insured by the conical burner, especially when the combustible mixture debit diminishes, may be considered very wide. It is important to highlight the characteristic of the conical burner of not generating back-ignition by comparison with the cylindrical tunnel burner where the flame return generated by the appearance of Karlowitz effect can be stopped only if special bodies are inserted in the burner, bodies characterized by a flow sections smaller than the minimal ignition diameter.

The experimental installation had the following main characteristics:

- gaseous fuel intake pipe interior diameter : $6 \mathrm{~mm}$;

- angle of the conical body of the burner : $12^{\circ}$; 
- refractory body made from cement with ceramic fibers;

- combustible : natural gas G20;

- mixture dosage : stoychiometric;

- gaseous combustible debit : $200 \mathrm{l} / \mathrm{h}$ and $100 \mathrm{l} / \mathrm{h}$;

- burner heat output: $2000 \mathrm{~W}$ respectively $1000 \mathrm{~W}$.

In figure 5 is presented a photo made from the opened end (a) and the corresponding thermography (b).

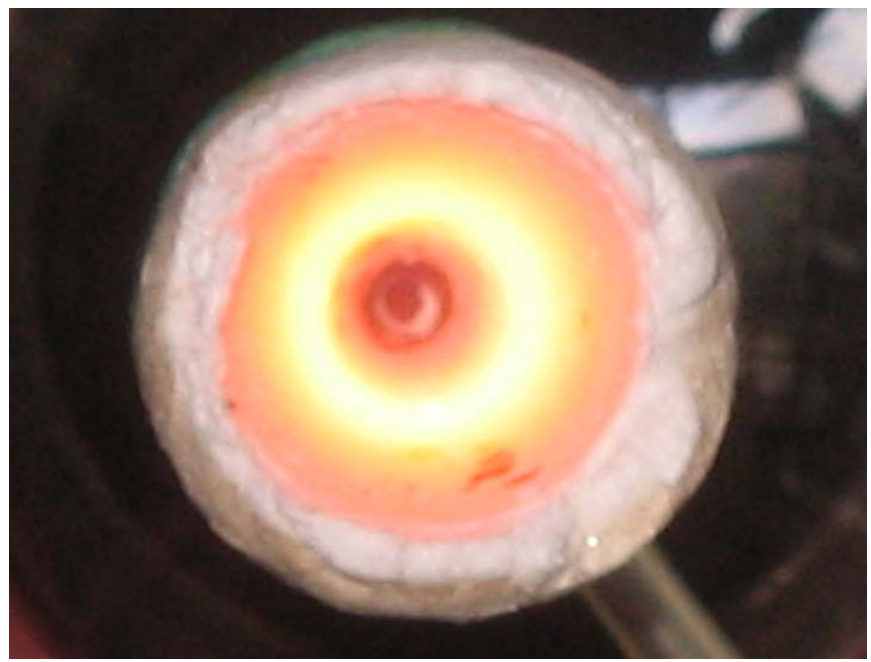

a

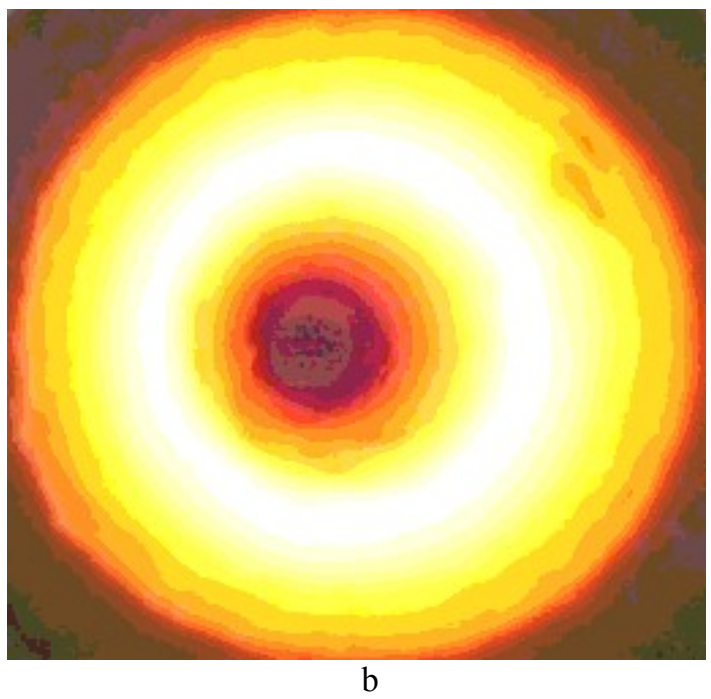

b

Fig 5. - Flame photo made from the opened end (a) and the corresponding thermography (b).

First of all it must be stated that the $2000 \mathrm{~W}$ thermal load for the burner did not generate any flame front braking or suspension, the burning process being stable during the whole experiment. Extrapolating the dataset we may appreciate that a conical burner with an intake nozzle of only $42 \mathrm{~mm}$ will reach a thermal load of $100 \mathrm{~kW}$.

The experimental research aimed to establish the temperature fields for the conical burner. Those fields provide basic information regarding the flame front stability, the burning speed and the thermal load for the burner's flow section. The measures were performed with a microthermoelement placed at different levels from the intake nozzle at different radial distances. The axial levels were between 5 and $40 \mathrm{~mm}$ with a $5 \mathrm{~mm}$ distance step and the radial positions were distributed from the centre of the section (axial position) to the conical wall with a $2 \mathrm{~mm}$ step. The measured temperature values for a semi section of the burner, generated by the flame front configuration and by the burning process zone, are presented in Figure 6.

The important intensification of the burning process is demonstrated by the short distance after intake that characterizes the ignition zone, situated at $15 \mathrm{~mm}$ axial distance from the nozzle. The wall extinguishing effect is visible and at a radial distance from the wall of only $2 \mathrm{~mm}$ the temperatures reaches the ignition level of approx. $800{ }^{\circ} \mathrm{C}$. The radial temperature field for this section is quite constant around this temperature, meaning that the whole section is in fact an ignition section. This geometry corresponds both to speed distribution in turbulent flows and also to the expected ignition phenomenon characterized by Karlowitz effect of self-turbulization.

The burning process develops, fact demonstrated by the raise of the temperatures, and reaches a maximum values distribution curve at an axial distance of $25 \mathrm{~mm}$. The $10 \mathrm{~mm}$ distance between ignition section and burning process ending may be assimilated with the flame front thickness. The $10 \mathrm{~mm}$ value for flame thickness was also expected for this type of intensified burning process, confirming once more the presence of the Karlowitz effect. 
The exponential trend of the temperature from ignition to maximal value, experimentally demonstrated by the temperatures measured in the $20 \mathrm{~mm}$ distance section, also confirms the burning process development, known as having these evolution from other different turbulent flame studies [8].
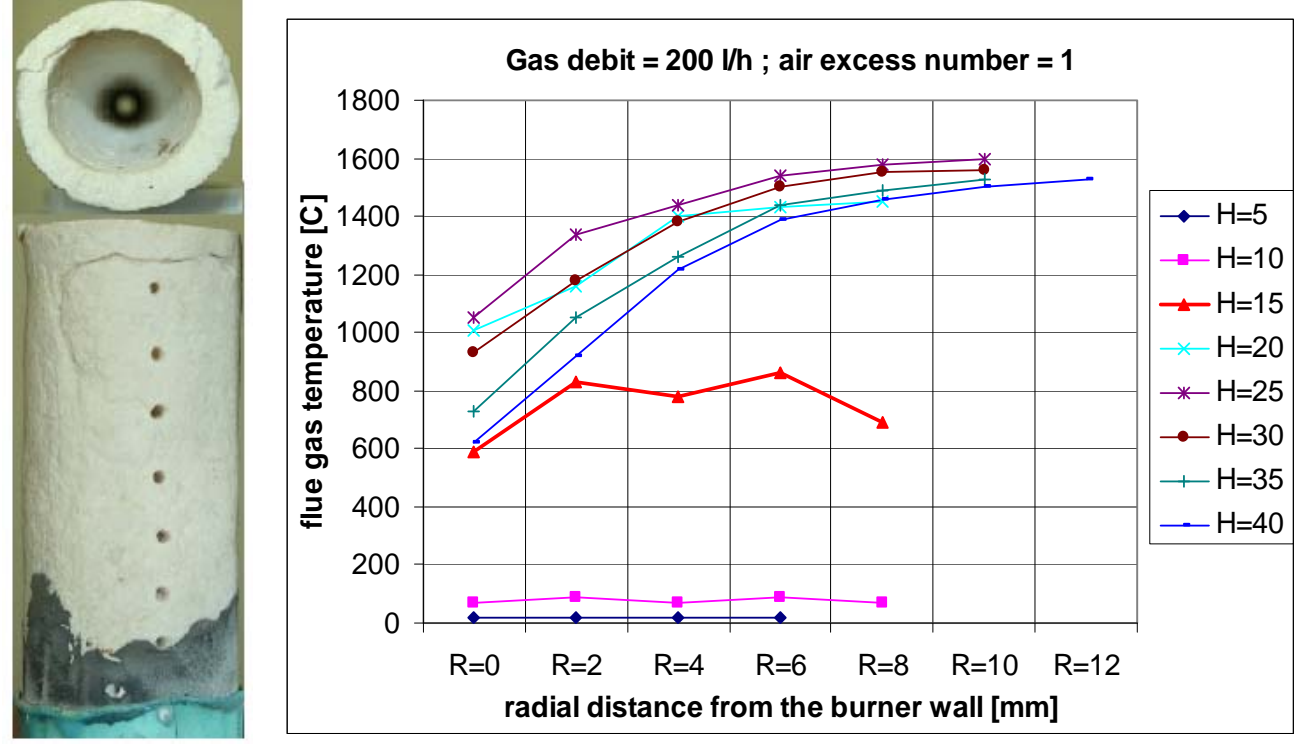

Fig 6 - Burner geometry (photos), distribution of measuring points and temperature fields

By expressing the experimental datasets in axial evolution for different radial distances from the axial position it may be also visualized the ignition section and the end of burning process section. In Table 1 , the temperature level of $700-800{ }^{\circ} \mathrm{C}$, corresponding to the ignition point for the gaseous combustible mixture, is reached at an axial distance of $15 \mathrm{~mm}$, for axial distances between 2 and $8 \mathrm{~mm}$. The maximum values for the temperatures are reached at an axial distance of $25 \mathrm{~mm}$ for all radial coordinates. The bold marked zone in the table corresponds to the burning process.

The thickness of the flame front in a turbulent burning process grows along with the turbulent intensity as a result of the flame front local curving (Damköhler model) and due to turbulent diffusion that displaces burning volumes that may constitute in local ignition islands (Growe model).

The additional turbulence generated by the Karlowitz effect in the conical tube is the explanation for the $10 \mathrm{~mm}$ flame front thickness value, corresponding to high levels of turbulence intensity, instead of the $2-3 \mathrm{~mm}$ flame front thickness that represents the normal values for the free flames at the same flow speeds.

Table 1

Axial downstream temperatures evolutions at different radial coordinates

\begin{tabular}{|c|c|c|c|c|c|c|c|c|}
\hline & $\mathrm{H}=5$ & $\mathrm{H}=10$ & $\mathrm{H}=15$ & $\mathrm{H}=20$ & $\mathrm{H}=25$ & $\mathrm{H}=30$ & $\mathrm{H}=35$ & $\mathrm{H}=40$ \\
\hline $\mathrm{R}=2$ & 20 & 90 & $\mathbf{8 3 0}$ & $\mathbf{1 1 6 0}$ & $\mathbf{1 3 4 0}$ & 1180 & 1050 & 920 \\
\hline $\mathrm{R}=4$ & 20 & 70 & $\mathbf{7 8 0}$ & $\mathbf{1 4 0 0}$ & $\mathbf{1 4 4 0}$ & 1380 & 1260 & 1220 \\
\hline $\mathrm{R}=6$ & 20 & 90 & $\mathbf{8 6 0}$ & $\mathbf{1 4 3 0}$ & $\mathbf{1 5 4 0}$ & 1500 & 1440 & 1390 \\
\hline $\mathrm{R}=8$ & 20 & 70 & $\mathbf{6 9 0}$ & $\mathbf{1 4 5 0}$ & $\mathbf{1 5 8 0}$ & 1550 & 1490 & 1460 \\
\hline
\end{tabular}

After the $25 \mathrm{~mm}$ section, the measured temperatures decrease, due to the lack of internal heat sources and because of the burner heat losses presence.

The flame front geometry (see Figure 2) is clearly plane in the section outside the boundary layer of the burner wall. The explanation for these specific flame front geometry is linked to the conical geometry of the burner along with the high intensity turbulence of the process that 
determines the burning process to develop on the uniform speed distribution existing in the flow, unlike the case of free flames were the flame shape is conical with the edge on the flow axis.

The plane form of the flame front, generated by the equality of the burning speed with the flow speed, states for the high thermal loads that characterize the section of the burner. For the experimental burner, on the flame front stabilization section of $1,2 \mathrm{~cm}^{2}$, the medium flow speed generated by the $2200 \mathrm{l} / \mathrm{h}$ of gaseous fuel mixture is about $5,09 \mathrm{~m} / \mathrm{s}$. This speed, characteristic for the conical geometry, self intensified, turbulent burning process, compared with the planar flame speed for methane stoychiometric mixtures that is $0,36 \mathrm{~m} / \mathrm{s}$, indicates a process intensification of about 14 times. This value is normal [6] and characteristic for the tunnel burners with Karlowitz effect and proves that the advantages induced by the conical form of the burner does not affect on its efficiency by respect to the burning process intensification.

As shown in figure 7 by the temperature fields for the case of $1001 / \mathrm{h}$ gaseous fuel intake, the general features of the process does not change. So, by realizing the measures with the same geometrical pattern as in the case of $200 \mathrm{l} / \mathrm{h}$ gaseous fuel intake, the same isothermal curves are obtained, stating that the burning process intensification by means of Karlowitz effect is also present at lower thermal loads.
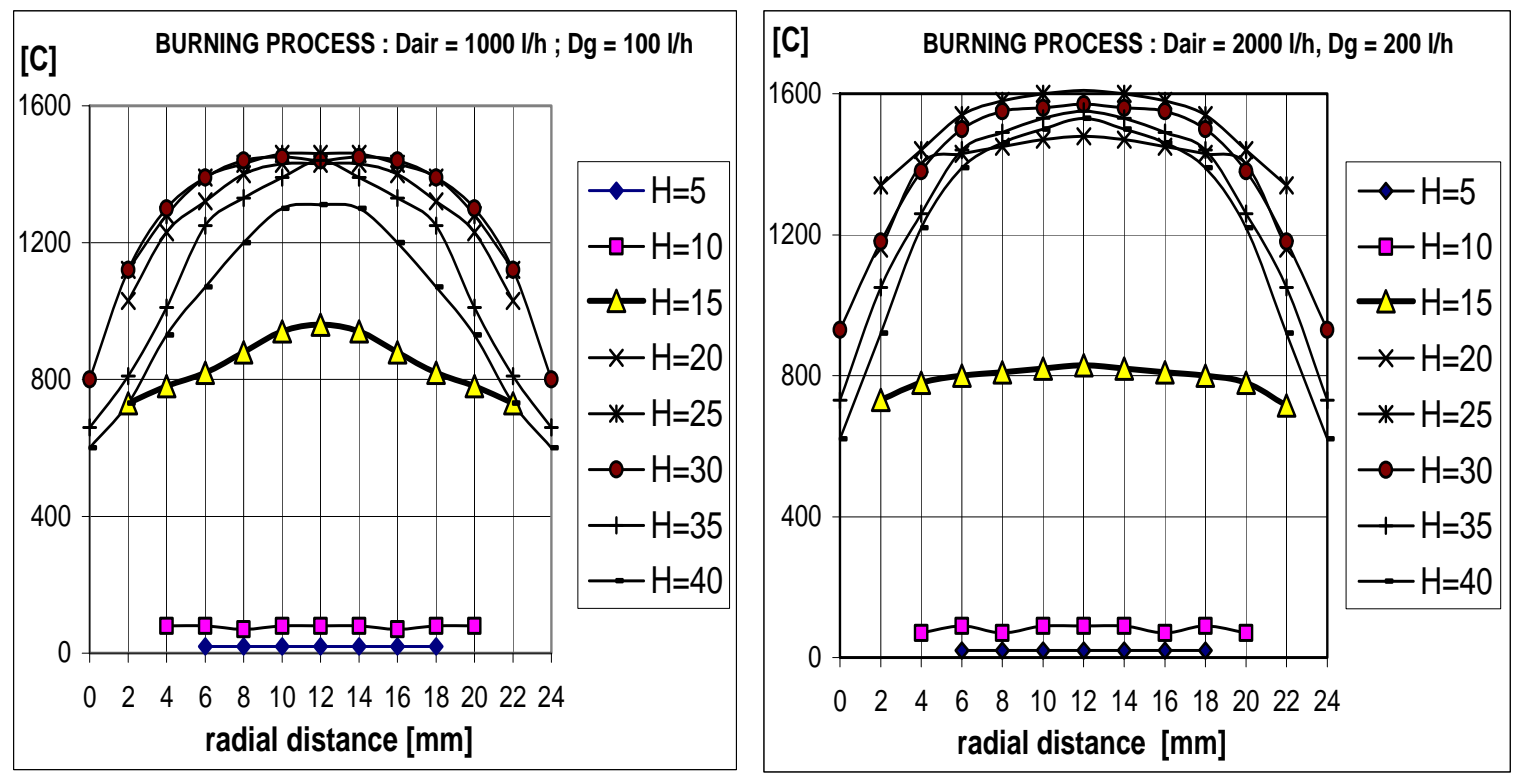

Fig 7 - Temperatures fields measured values for two thermal loads

\section{Conclusions and discussions}

From the point of view of supplementary turbulization generated by the non-slip boundary conditions at the wall the flow section enlargement generated by the conical geometry of the burner can be neglected in terms of overall axial deceleration. Anyhow, the component of speed difference projection on radial direction (see figure 4 and equation 5) will induce an increase of the flow energy, but compared with the axial flow energy, the increase is quite of little importance, due to the cone angle that is limited to $12^{\circ}$.

Calculating: $\tan ^{2}\left(\frac{\beta}{2}\right) \leq 0.011$ for $\left(\frac{\beta}{2}\right) \leq 6^{\circ}$, it results an increase of the axial flow energy of maximum $1,1 \%$ for the conical burner case, compared with the cylindrical burner case. So, the turbulent burning speed increase, which is directly linked to the self-turbulization process, will reach the same values in either cylindrical or conical burner. 
The conical tunnel burner is an improvement of the cylindrical tunnel burner because, by maintaining all its advantages by means of burning intensification, it may also insure the flame stabilization in a wide range of regulation and with considerable diminished pressure losses.

We consider that the first applications of the conical tunnel burner will be for boilers, especially for condensing boilers, but also for furnaces and other technological applications that require large regulation domains and quick thermal responses and maybe even for gas turbines burning chambers.

The important self-turbulization that occurs in the conical burner makes the burning process speed to increase, for methane-air stoichiometric mixture, from the usual values of 1 to $2 \mathrm{~m} / \mathrm{s}$, characteristic for turbulent free flames, to $5 \mathrm{~m} / \mathrm{s}$. In those conditions the sectional thermal load for the conical burner reaches values averaging $18 \mathrm{MW} / \mathrm{m}^{2}$.

The ignition of the conical furnace burner can be realized in very stable conditions because of its geometry with variable flow section that can determine the existence of a stable ignition contour in the boundary layer of a flow section between the infeed nozzle and the exit section. This fact is particular for the conical burner, the cylindrical burner having no possibility of stabilizing the flame front somewhere along the flow without proper special stabilization devices such as annular recirculation chambers or anti-backflame structures.

The flame front in the conical furnace burner is plane and very stable, the backflame phenomenon being (in general, for the tested range of thermal powers) constructively avoided, without the need of any additional devices.

Because of the stabilization process, priory described, the conical furnace burner allows wide regulation domains (down to 1:10 of the nominal load), significantly wider than in most technical cases (1:2 of the nominal load for normal forced draught burners and 1:5 of the nominal load for vortex burners). Practically, the regulation domain for the combustible mixture debits is given by the ratio between the surface of the exit section of the burner and the surface of the intake section of the burner, just after the infeed nozzle.

An important advantage is the low pressure losses that characterize the conical burner compared to the tunnel burner (cylindrical). The fact is due to the flow section enlargement after stabilization of the burning process that allows the deceleration of the flue gases debit.

In further researches we intend to enlarge our study of conical furnace burners' applications for the cases of other thermal loads and types of boilers, for direct mixture air heaters and also for energetical facilities.

This paper was presented at EENVIRO 2014 Conference.

\section{References}

[1] Lewis B., Pease R., Taylor H. (1956). Combustion processes, Ed. Princeton Univ.

[2] Akkerman V., Bychkov V., et al. (2006). Flame oscillations in tubes with non-slip at the walls, Combustion and Flame 145, (pp. 675 - 687).

[3] Bychkov V., Petchenko A., Akkerman V., et al. (2005). Theory and modeling of accelerating flames in tubes, Phys. Rev. E 72.

[4] Akkerman V., Bychkov V., Petchenko A., et al., (2006). Accelerating flames in cylindrical tubes with non-slip at the walls, Combustion and Flame 145, (pp. 206 - 219).

[5] Bychkov V., Akkerman V., et al., Flame acceleration at the early stages of burning in tubes, Combustion and Flame.

[6] Akkerman V. (2007). Turbulent burning, flame acceleration, explosion triggering Umea University Department of Physics.

[7] Antonescu N., Stanescu P.D., Antonescu N.N. (2002). Burning processes - theoretical and experimental bases, publishing house Matrix-Rom Bucharest, 317 pages.

[8] Antonescu N., Burning processes with peripheral stabilization in tunnel furnace burners - Energetical Studies and Researches - publishing house of the Romanian Academy - tome XII, nr.4, (pp. 416-434). 